\title{
Roles of Artificial Intelligence (AI) on COVID-19 Pandemic Crisis Management Policies
}

\author{
Murat Onder, Ankara Yildirim Beyazit University, Turkey \\ Mehmet Metin Uzun, University of Exeter, UK* \\ (iD https://orcid.org/0000-0002-2000-9585
}

\begin{abstract}
The new coronavirus (COVID-19) crisis has had a devastating impact across the world. Public administration discipline addresses emergency crisis management in various ways and dimensions. This article seeks answers to the question: "How can AI contribute to crisis management policies to fight against COVID-19 and its impacts?" To this, the techniques and methods of AI in fighting against the COVID-19 virus will be explained in various dimensions. AI can make significant contributions in the preparation, mitigation-prevention, response, and recovery policies in the COVID-19 pandemic crisis. If adopted, AI can be used to find better treatment routes and drug development. Equally, policymakers can benefit from AI as decision support to reach high-quality decisions through fast and accurate data. The paper concludes that governments should create and implement effective AIbased crisis management strategies to fight against the epidemic locally, regionally, nationally, and internationally with a multi-level governance perspective.
\end{abstract}

\section{KEYWORDS}

AI, COVID-19, Crisis Management, Preparation Mitigation Response Recovery, Public Policy

\section{INTRODUCTION}

The new type of coronaviruses (COVID-19) has had a devastating impact across the world. The pandemic has shaken health systems in many countries, disrupted socio-economic activities, and led to the closure of many learning and economic institutions. The European Parliament Report (2020) addressed the potential social and economic effects of the epidemic in several dimensions. The report emphasizes that health, agriculture, tourism, and travel are some of the sectors that will be directly and dramatically affected by the pandemic (Delivorias \& Scholz, 2020). Critical decisions should be made about the short and long-term planning and management of the COVID-19 outbreak (Correia, 2020).

The research community and policymakers of governments and health management policies were unable to pay enough attention to the roles of high-techs in healthcare and adopt and benefit from them rapidly. Nevertheless, public administration research has included some valuable perspectives on governments' position in implementing and managing new innovations of digital technology (Paulin, 2017; Ben Rehouma, 2019; Dickinson, 2018). Simon (1965) highlighted the significance of qualified data as a backbone of the decision-making process. Hurley and Wallace (1986) mentioned early development of AI and offered experts system as decision aids for public managers. Big data, machine learning, and deep learning techniques achieve faster and more optimal results compared to 
humans in processing existing data and making better policy decisions (Onder \& Saygll1, 2018). AI has proved successful in establishing contextual relationships between various huge amounts of data. Therefore, AI applications and techniques are integrated in many aspects of the health sector such as disease diagnosis, drug development, and genome editing techniques (Chowdhury \& Chakraborty, 2017). Moreover, AI can be used effectively in filtering patients' past medical records and establishing correlations between patient similarities. AI based technology can also detect what types of care work better for a particular group of patients (IBM, 2020).However, it is not technology alone that will make a difference, but also the knowledge and collaboration of AI experts and government officials who make important policy decisions matter.

Most of the time, crises have been observed at the local or regional level, and crisis management literature generally tries to understand the management of crisis at the micro level: local or regional. However, the COVID-19 pandemic has surpassed national and continental levels to become a macroglobal crisis. In other words, the uniqueness of COVID-19 pandemic crisis is that it has higher uncertainty and a higher degree of transboundary fatalities. Therefore, this article investigates the question of "How can AI contribute to crisis management policies to fight against the COVID-19 and its impacts?" To do this, different AI methods, applications, and tools used in different countries in fighting COVID-19 virus will be provided by integrating previous research and theories from literature about crisis management policies. The crisis management discussed in this article emerges from a review of the literature on the "AI" and "COVID-19". To review the literature regarding COVID-19 crisis management, electronic academic databases were searched by using keywords such as "AI", "big data," "crisis management," "disease outbreak," "prevention policy," "digital governance," "scenario evaluations", "recovery" and the combinations of these keywords about COVID-19 pandemic. Fighting COVID-19 pandemic with AI will be considered in terms of crisis management framework in preparation, prevention, response, and recovery policies perspectives.

\section{COVID-19 PANDEMIC AND CRISIS MANAGEMENT WITH BIG DATA AND AI}

Pandemics often have severe consequences across the world. Public administration discipline addresses emergency crisis management in various ways and dimensions (Christensen et al., 2016; French \& Raymond, 2009; Henstra, 2010; Jung et al., 2019). Effective crisis management is a central responsibility of government; however, it is a difficult task to fulfil. The speed and success of the public policy design and implementation process in times of crisis are closely related to governance capacity (Yildiz \& Uzun, 2020:11). Adequate governance capacity and credibility are necessary to build a well-founded crisis response system (Christensen et al., 2016: 887; Hart, 2001). In this context, public administration and policy offer valuable insights in 'emergency management,' 'evaluating public safety risks,' and 'recognizing gaps and ensuring that resources' for successful response and quick recovery (Henstra, 2010:236). Additionally, crisis response systems based on direct shared connections are critical to stable surveillance systems for building strong local governments, enhancing effective awareness, and mobilizing resources in emergency preparedness and recovery systems. Crisis management is a process in which an organization copes with a crisis before, during, and after the emergency. It involves identifying, evaluating, understanding, and dealing with a crisis (Christensen et al., 2016:888). Therefore, policymakers need to use knowledge and recommendations available to formulate policies that will optimize positive social and economic benefits in their communities (French \& Raymond, 2009: 829).

Public policies designed to cope with problems and manage the crisis are classified into four main categories as preparedness, mitigation, response, and recovery policies (Henstra, 2010:237; Deliorias \& Scholz, 2020: 6; French \& Raymond, 2009: 829). Handling the responsibilities of crisis management is expected to be carried out by public organizations together with the private sector and NGOs collaborations (Lai, 2012:8; Jung et al., 2019). Crisis management is mostly regarded as wicked since it typically transcends organizational boundaries with multiple levels, sectors, actors 
(Head and Alford, 2015). Most public policies to curb pandemics have been prepared at a national level and driven by national priorities (Kamradt-Scott \& McInnes, 2012: 106-107) that slow the global struggle against pandemics. Governments are responsible for providing citizens effective healthcare and providing public services and programs with the greatest benefit and optimum cost. Many of the problems of emerging technology, including AI, are not straightforward to see. Technological advances such as AI have significant consequences for security, regulation, or other policy procedures. Therefore, multi-level governance perspective (Yildirim \& Onder, 2019), crisis response and management can benefit from advancements made in AI. Multi-level governance practices are equally complex, and AI technology can help improve coordination within government agencies themselves and their interaction with external actors especially during crises (Christensen et al., 2016). During the pandemic crisis, digital governance had significant role in public health management in many areas by supporting epidemic forecasting and decision making. New generation technologies such as AI, QR code (Wang et al., 2020), geographical tracking and mapping (Kamel Boulos \& Geraghty, 2020), IoT (Rahman et al., 2020), telemedicine (Mann et al., 2020) and blockchain played an important role in responding to public health problems (Ting et al., 2020). Data is the first step in improving any method for treatment or administration (Cohen et al., 2020). The analysis of big data in public policy perception focuses on capturing "multi-modal" huge amounts of data generated by both public and private providers.

The following systematics of administrative functions can be described in the application of big data in the public sector: (1) Government monitoring - detecting violations (e.g. legal incompliance) and taking appropriate action; (2) Public regulation - controlling social conduct and shaping social relations by means of permits, prohibitions, or orders; (3) Delivery of public utilities - the procurement of such facilities or services, which include infrastructure such as roads (Maciejewski, 2020).

$\mathrm{AI}$ is one of the best achievements of the millennium and has a prospective positive impact on public administration (Ojo et al. 2019:159). AI has increasingly become an important tool in public management activities such as "decision-making, big data processing, public services, and public safety" (Valle-Cruz et al., 2019:91; Bullock,2019: 3; Barth \& Arnold, 1999: 341). AI-based technology focuses on automate human problem-solving strategies to create more effective solutions (Onder, 2020). European Commission (2020:2), "White Paper" report defines AI as "a collection of technologies integrating the power of data, algorithms and computing". According to the report, AI ecosystem improved healthcare system by reducing the costs of providing services such as transport, education, energy and waste management. Similarly, OECD (2019) encourages incorporating AI into the entire cycle of decision making and service design. When AI and deep learning technologies progresses, it would be necessary to automate further administrative and process-driven activities, improving decision making in the public sector and gain access to more participate public engagement (Kaya,2019). AI will contribute to better performance, greater productivity, and more favorable health outcomes. Moreover, AI can be used as an important tool in ensuring human security and fighting against crises (OECD, 2019: 63-68).

In countries where they have been adopted, AI tools and applications have been successful in combatting COVID-19 at various stages. This requires the recognizing the significance of information and big data systems. AI based on these data (Sousa et al., 2019) is a core component of public health management systems through all four crisis management phases. Therefore, AI may surpass human solutions in many ways even with current AI applications, and managing pandemics is and should be one of them. AI has the ability to contribute to decision making and implementation process during the crisis in the following ways (Onder, 2020:6-7; Kushchu, 2020:3; Mergel et al.2016);

- To collect data in different ways multiple sources in various forms regardless of language, text, image or video streams,

- To work with multidimensional complex big data,

- To priorities or optimize, 
- To analyze the data to find patterns that can be used for classification (measure of relevance) or prediction (assertion about future),

- To disseminate solutions or information about problems to intelligently selected target group as and when needed and according to needs and demands of these target groups individually, segmented carefully or totally

The following sections will evaluate crisis management policies of preparation mitigation, response, and recovery policies.

\section{Preparation Policies}

Emergencies happen suddenly, therefore, effective responses are based on getting prepared before they happen. Lack of preparedness increase the extent of crisis. Preparedness policies include anticipatory initiatives that improve public response capacity efficiently in crises (Henstra, 2010:237). Preparation policies evaluate various aspects such as leadership, risk assessment, risk reduction, emergency preparedness plans, protection plans, and scenario evaluations, etc. (WHO, 2009). Preparation involves efforts that will ensure availability of human, financial, and technical resources that will facilitate emergency response services and logistics. This also helps develop communication strategies, educating health workers and the public.

In recent decades, more focus has been directed to the indicators of preparation for a crisis management strategies (Sun \& Xue, 2020). Pandemics require a well-designed set of planning and prevention policies. Some of these policies have been researched in the field of medicine. However, how AI or related emerging technologies can help crisis management phases with specific data processing capability in macro policy making is still understudied. AI can be an essential part of intelligent scenario analysis, risk evaluations, and prioritization. While machine learning is powerful for big data heavy analysis, evolutionary methods such as genetic algorithms can be used for optimization, sharing, and allocation of resources such as staff and supply planning, and finances. Critical planning requires determining possible ways that the infections can spread geographically and ways of minimizing social contacts/distances. Using disease-related and other relevant data, AI can help discovery of various strategies and their evaluations, and as such, can be a useful tool for understanding which social strategies would lead to minimal losses of lives (Kushchu, 2020: 5). On the other hand, Chinese scientists have developed a system that predicts how much the virus epidemic will spread and how long the epidemic will last. The AI system has been correlated with statistics focused on the periodic COVID-19 epidemic numbers published by the Chinese National Health Commission based on the 2003 SARS pandemic. An AI system based on the SARS datasets; it provides additional observations for the pandemic expansion (Yang et al., 2020).

Through the use big data, AI technologies can be essential in efforts such as faster diagnosis of the virus to the distribution of respiratory equipment in the hospital to the primary patients. AIbased applications discovered the progress and dimensions of the epidemic earlier. A Canadian-based platform, BlueDot is an AI system that was developed to detect the spread of infectious diseases. This platform issued an early warning of an unusual pneumonia occurring in Wuhan city in December 2019, nine days before the World Health Organization (WHO). BlueDot became the first company to report the new type of corona virus known as COVID-19. BlueDot uses an AI-oriented algorithm that examines foreign language news reports, disease reports, and official statements to alert customers to avoid dangerous areas such as Wuhan. Similarly, in the U.S., AI-based system Metabiota (2020) closely monitoring and analyzing the COVID-19 epidemic in several ways, including through a trueto-source digital surveillance system and a global disease spread model reports that a COVID-19 has been expanding since January 2020.

Within the scope of the COVID-19 epidemic, the leading AI institutes of the USA (Allen Institute for AI) have prepared the COVID-19 Open Research Dataset (CORD-19). This dataset includes 29,000 articles, including 13,000 full-text pieces of medical literature, related to the corona virus. Additionally, 
CORD-19 was created with the natural language processing (NLP) technique to support the ongoing fight against infectious disease and create new understandings (Hollister, 2020). Scenario evaluations via disease models and big data to develop epidemic intelligence can help determine the critical time to respond and prioritize the most effective actions by looking at genetic data and population movement. For example, AI-based systems can help to determine and evaluate who should be tested when a large number of potential patients exists. AI can support decisions affecting strategic and action plans for efficient use of finances by providing priorities and the right form of partnerships and cooperation with the public, private, and nonprofit organizations. Concordantly, organizations such as IBM, Amazon, Google Cloud, Microsoft, Massachusetts Institute of Technology, NASA will use their existing facilities to fight against the coronavirus. The multi-stakeholder governance model created by the public, industry-leading companies, and academia is important in developing a global pandemic strategy (Bullock et al., 2020:10). However, international cooperation between countries regarding data sharing is the critical factor for successful global preparation and action strategies.

Mitigation or Prevention Policies

Mitigation strategies focus on preventing or reducing the impact of emergencies on people and economy. This phase is characterized by activities that focus on the identification and management of risks, starting with a situation analysis. Mainly, two types of risks, spark risk and spread risk must be known in controlling and reducing the spread of the pandemics. Most of the critical activities are related to early detection of these risks (Kushchu, 2020: 4). Mitigation programs, detection systems, health care, transportation of dangerous materials, and land use descriptions are key topics of mitigation policy (Henstra, 2010:240). Some of these items could be standard as simple practical measures such as hygiene for prevention and control at the clinical centers and hospitals, but the organization and education of such activities can be supported by analytical tools, and at the more complex level by employing AI techniques. Furthermore, AI-based mitigation policy requires early discovery, establishing action plans to monitor high risk areas of spark infections, preventive measures of control, improving resistance through communication and regulations, and carrying out risk analysis periodically or for suddenly emerging ones (Kushchu, 2020: 5). In this context, AI systems can actively be used as predictive and prevention analysis to measure the progression of the disease. Scientists have developed an artificial intelligence application that detects the risks of acute respiratory syndrome (ARDS) in patients' lungs. AI, trained using COVID-19 patient data in China, has a 70\% -80\% success in predicting which patients are at risk of ARDS. This provides an important advantage for rapid clinical decision making and governmental resource allocation accordingly (Jiang et al., 2020). Therefore, policy makers play an important role by using fast and advanced AI-based preventive measures for public health as a policy instrument. New AI supported programs had already been used in detecting infections and issuing early warnings. If well integrated across the border, this will be very helpful for effective network management throughout the nation or the globe. For example, mobile applications data sets analyzed by an AI system can classify and subdivide people into categories of no risk, low risk, moderate risk, and high risk. The high-risk cases recognized can then be quarantined earlier and thus the chance of spreading the virus reduces (Rao \& Vazquez, 2020:826). In various countries, AI has also been used to monitor temperature using thermal cameras. Furthermore, AI-Based technology track patients and their connections with facial recognition and mobile devices, and control the infected person's location data and itinerary through the smartphones (Jakhar \& Kaur, 2020).

Screening of infected patients is a crucial in fighting against COVID-19. In early studies, it was found that there were abnormalities in chest radiograph images of patients infected with COVID-19. COVID-NET, the deep learning application developed in this framework, provided promising results in the detection of infected patients using chest radiograph images. The COVID-NET system was 
created by training with a dataset consisting of 5,941 chest radiograph images in 2,839 patient cases from the open access data pool (Wang \& Wong, 2020). Another example of used AI tools, Gozes (2020) analyzed "Advanced AI disease evolution method for COVID-19." The deep learning method of CT (computerized tomography) image analysis was developed to "detect, characterize and monitor the progress of COVID19". This deep learning image analysis system accurately classifies $96.4 \%$ of patients' data sets (for infected and non-infected cases). The system measures the progress of the disease over time by measuring the 'corona score' of patients. This shows that AI can be used as an effective tool for screening and early detection of patients infected with the COVID-19 pathogen (Gozes et al., 2020). Recent studies of COVID-19 emphasize that image datasets provide important clues to disease detection. Cohen et al. (2020) created the COVID-19 CXR image data collection of 542 patients from 26 countries. As a result of AI-based examination of this dataset, the severity of pneumonia, the survival outcome and the need for the intensive care unit were categorized (Cohen et al., 2020: 2-9). Luckily, international data pools and AI collaborations started to be established in the treatment of COVID-19. Imaging COVID-19 AI is a multi-center AI project created to speed up the diagnosis of corona virus. The project community develops an accessible AI dataset to the public with imagery from various hospitals and organizations in European countries according to Imaging COVID-19 AI which attempts to optimize the analysis of COVID-19 on CT scans and determine the pressure of infection in contaminated patients' lungs. The AI model designed would be accessible to all eligible medical facilities and research laboratories. Furthermore, the project is aimed to be expanded in European hospitals as soon as possible. (Imagining Covid-19 AI, 2020).

\section{Responding or Fighting the Pandemic}

There are several key elements in the emergency response policies. First, emergency operation and emergency response services intervention are very critical. On the other hand, the evacuation plan, coordination and communication strategies, surveillance policy, search and rescue, and public emergency information are important parts of the response strategies (Henstra, 2010:241), too. Responses to pandemics require turning all plans into actions, and such responses must be in proportion to the severity, scale, and intensity as well as the changing nature of the outbreak. During emergencies, some of the most significant situations that AI seems to be useful include infection prevention and control, managing direct support actions, and managing the public (Kushchu, 2020: 8). "Infection prevention and control" involves discovery of vaccines and antivirals, management of testing the relevant members of the public, management of treatments, contact tracing, and isolations and containment measures. "Managing direct support actions" involves workload of the health workers and other key personnel, procurement and allocation of supplies, communication among organizations and health workers, and communication with confirmed and potential patients. "Managing the public at large" includes isolation measures, public safety, security and provision of essential needs such as food and hygiene, and social and psychological support for the population. All of these actions create complex and dynamic interrelated systems that need to be well managed by adopting various AI techniques to find answers to issues related to priorities, optimization, categorization, and prediction.

Institutional, political, and social contexts play an important role in preparing and applying public policies (Jresiat, 2012:98; Christensen et al., 2016:889; Onder \& Nyadera, 2020:5-6). The implementation might be different from strategic plans because of networks and practices (Choi \& Brower 2006; Aydin et al. 2020). The institutional collective action theory suggests that the operational costs of tracking and executing strategic direction and the contractual partnership commitments might prohibit organizations' from working together to produce better results (Feiock, 2013). This is one of most significant strengths AI can contribute with monitoring to reduce transaction cost of sustaining collaborations.

Real Time Disease Models and Response Accuracy

The system often works based on real time data, and solutions are generated fast to effectively control the infection and spread (Kushchu, 2020: 9); 
- Data generated from various sources including social media in various forms, often as text and using NLP, are used for effective responses. Such data include location- relevant weather, and demographics - especially age, previous illnesses, symptoms, and treatment responses.

- Coordination and communication can be supported through prediction and classification using travel and traffic data, workload on clinics, need for supplies, social distancing, and data summarization and dissemination for communication to needing parties.

- Intelligent genomic sequencing can help accuracy and speed in identifying virulence factors, nature of the spread, and the sources - natural, accidental, or deliberate human activities.

- AI systems, reliable data, and their analytics increase speed and accuracy for precise responses rather than reactions.

\section{Vaccination Development and Drug Discovery}

The process of producing drugs related to COVID-19 is complicated. AI-based technologies have actively been used in the treatment of diseases caused by COVID-19 and "drug discovery." The most important role of AI algorithms is to narrow the hypothesis space to be tested and prioritize the most probable hypotheses to work in the laboratory. For example, for COVID-19, AI algorithms can be used to estimate drugs that are most likely to affect target proteins among all available drugs. AI entrepreneurs and companies focus on treatment options to develop against the virus. Moreover, machine and deep learning techniques offer faster and less costly ways to find better treatment options. Scientists remark that the most optimal result for finding the drug will consist of many different components that will be revealed by AI-based technologies (Bullock et al., 2020). AI-driven data networks can facilitate rapid drug development (Stebbing et al., 2020). As a "quantum computer," IBM Summit with its 200 quadrillion calculation speed, considered the world's most powerful supercomputer, has performed 8,000 different simulations to analyze which drug components can effectively stop the virus from infecting host cells. As a result, 77 small molecule drug components that will benefit the treatment of the virus have been identified (Andrew, 2020). British AI technology solution company Benevolent AI has also found a 6-component drug constituent by analyzing the numerous links made in the scientific literature with machine learning techniques. The company has released a study showing several compounds that are likely to be successful in combination with biochemical simulation based on the datasets of the corresponding virus proteins the algorithm was designed to define (Richardson et al., 2020). Furthermore, Hong Kong-based biotechnology company Insilico Medicine has announced that it has created an AI-based platform to produce new molecules with the potential to prevent virus replication. (Zhavoronkov et al., 2020). The process of producing drugs related to COVID-19 is still complicated. However, deep learning techniques and artificial neural networks remain a source of hope for the treatment methodology.

Similarly, Semi-autonomous drones make a significant contribution to fight against COVID-19 by minimizing human interactions and delivering emergency medicine. In search and rescue operations around the world, drones have become tools to help view large areas and maintain communications in difficult areas. These features are critical to control the crowded cities in the COVID-19 panic and help to establish healthy communication channels. For example, in India, the government of Karnataka uses drones to sterilize public facilities in places with cases reported, such as hospitals and metro stations. Similarly, Ghana uses drones to deliver COVID-19 test kits (Hussain, 2020). With the help of drones, the authorities can inform people and make a public announcement or broadcast such as "wearing a mask, staying inside and temperature check", as well as controlling large areas efficiently. To sum up, the drones and robots have become important tools for complying with social distance, spraying disinfection, medicine, and grocery deliveries (Chamola et al., 2020:39-41). Recovery Policies

Recovery policies focus on helping to restore the damaging effects of disasters and rehabilitate a population after crises. In this phase, all efforts are directed towards getting things to run normally. It involves providing physiological, social, and economic support for the wellness of affected persons. There is always a risk of new sparks, spreads, or mutations. From this perspective, recovery policies 
are significant for post-pandemic situation because recovery policies need to be implemented quickly to prevent the second wave of outbreaks. Therefore, the recovery processes must include a continued monitoring for such incidences at all times, and with effective technologies such as AI. Communicative and interactive AI systems help react to the health emergency through personalized information, contacting high-risk patients, rehabilitating, medical treatment, and learning. Virtual assistants and chatbots have been developed to support healthcare organizations such as the American Red Cross (OECD, 2020).

AI techniques can be used to calculate the size of the estimated socio-economic, political, physiological damage caused by the COVID-19. On the other hand, AI solutions can be used to collect and analyze data in the epidemic process and to create a new strategy for possible future epidemic. In the strategy of the China regarding the COVID-19, state and private sector cooperation (such as Alibabacloud) is an important example of the efficient use of AI-based technology for public health.. Not only was the 'data mining' behind this success, but so was the multi-level governance approach connecting private and public organizations for the same cause of beating the pandemic. It was effective and seemed to work very well in managing health management and recovery of COVID-19 in a short period of time (Uzun, 2020) (Table 1).

\section{CONCLUSION}

The magnitude of COVID-19 pandemic shows that we have not learned enough from our past experiences. Since it was first detected in China, the new type of corona virus, COVID-19, has spread rapidly and continuously to more than 200 countries in less than three months. Public management scholars looking for various solutions related to crisis management offered some policy alternatives. Moreover, governments' policies have to find out 'rapid and effective' solutions in this type of fatal pandemic cooperatively. In the COVID-19 crisis, where developing 'new technologies' are tested, the performance of AI-based technologies such as machine learning and deep learning have predicted the spread of infectious diseases and produced solutions that should be recognized, and lessons learned from.

$\mathrm{AI}$ techniques and prototypes have served as a convenient way of sharing data. Therefore, it is predicted that AI will help make higher quality decisions, as it will contribute to faster and more accurate data for policy makers. After the COVID-19 pandemic, government's responsibility increased more than before because of range and long-term impact of the pandemic. This crisis period of humanity provides an opportunity to demonstrate how AI technology may bring 'hope' for the future crisis. If so, big data appears to be one good solution to prevent big government (Hoffman, 2016:684). As O'Malley (2014:557) said, "using Big Data to give the people a government that is theirs, where we fail, we are accountable; where we succeed," is helping us to govern people according to will of people more effectively by the help of big data and AI.

Data is the backbone of AI, and this demand has driven data collection in a self-reinforcing cycle. The integration of AI and big data can offer numerous advantages to financial, scientific and social development. However, it might also create risks for individuals and society as a whole, such as widespread surveillance and monitoring, lack of data governance and polarization (European Parliament, 2020). AI is an effective problem-solving tool if used appropriately, and the risks posed by this technology need to be well identified. In fact, many companies (i.e., AMAZON, Google, Facebook, and Microsoft) allocate millions of dollars for AI-based investments. This could lead to companies becoming more powerful and monopolies in the future. Therefore, governments should regulate and monitor AI, plan their AI investments, support AI-based solutions in crisis management policies, and analyze the risk factors of new technology.

Previous expertise in repairing international strategies was necessary to tackle global concerns, given the extent of COVID-19. However, strategy, preparation, and regulations have been primarily determined by regional goals and scales. The inconsistent local public safety response plans and 
Table 1. Crisis Management Public Policies to Control COVID-19 Pandemic

\begin{tabular}{|c|c|c|}
\hline $\begin{array}{l}\text { Type of } \\
\text { Policy }\end{array}$ & Dimensions and Tools & Use of AI Fighting Against the Pandemic \\
\hline \multirow[t]{3}{*}{$\begin{array}{l}\text { Preparation } \\
\quad \text { Policy }\end{array}$} & Preparedness Plan & $\begin{array}{c}\text { Epidemic Spread Simulation-Modelling } \\
\text { Scenario evaluations via disease models } \\
\text { Logistical Planning and Economic Interventions } \\
\text { Genetic algorithms } \\
\text { Big data solutions } \\
\text { Image Data Analysis - Textual Data Analysis }\end{array}$ \\
\hline & Risk Assessment & $\begin{array}{l}\text { Modeling potential size and speed of the spread } \\
\text { Various scenarios for creating a risk strategy } \\
\text { Patient Prioritization }\end{array}$ \\
\hline & Diagnosis of The Virus & Epidemic Detection System; i.e. BlueDot \\
\hline \multirow[t]{3}{*}{$\begin{array}{l}\text { Prevention } \\
\text { Policy }\end{array}$} & $\begin{array}{l}\text { Infection Prevention and } \\
\text { Control }\end{array}$ & $\begin{array}{c}\text { Developing strategies by making use of hospitals, travel and traffic data, } \\
\text { i.e. Imagining COVID-19 AI } \\
\text { Automated Primary Care }\end{array}$ \\
\hline & $\begin{array}{l}\text { Screening of Infected } \\
\text { Patients }\end{array}$ & i.e. COVID NET (Deep learning method of CT (computerized tomography) \\
\hline & $\begin{array}{l}\text { Epidemic Monitoring } \\
\text { System }\end{array}$ & $\begin{array}{l}\text { Police surveillance } \\
\text { Screening and Diagnosis } \\
\text { Patient CT scans } \\
\text { Predictive and prevention analysis to measure the progression of the disease } \\
\text { Controlling Misinformation \& Online Harms }\end{array}$ \\
\hline \multirow{6}{*}{$\begin{array}{l}\text { Response } \\
\text { Policy }\end{array}$} & Emergency Operation & Isolation Management: i.e. Alibaba Pay App \\
\hline & Sterilization & UVD-Robots \\
\hline & $\begin{array}{l}\text { Pharmaceutical } \\
\text { Research }\end{array}$ & $\begin{array}{l}\text { IBM Summit, } \\
\text { Google DeepMind, }\end{array}$ \\
\hline & $\begin{array}{l}\text { Data Science for } \\
\text { COVID-19 }\end{array}$ & $\begin{array}{l}\text { COVID-19 Dashboard COVID-19 Biomedical Data } \\
\text { Bibliometric Data Collection }\end{array}$ \\
\hline & $\begin{array}{l}\text { Pandemic Surveillance } \\
\text { Policy }\end{array}$ & Sharing Data Various Sources: i.e. Open Research Dataset (CORD-19) \\
\hline & $\begin{array}{l}\text { Communication- } \\
\text { Coordination } \\
\text { Workforce Support }\end{array}$ & $\begin{array}{l}\text { i.e. Chatbot Communication with confirmed and potential patients. } \\
\text { Coordination among organizations and health workers } \\
\text { i.e. robotics \& drones }\end{array}$ \\
\hline \multirow[t]{2}{*}{$\begin{array}{l}\text { Recovery } \\
\text { Policy }\end{array}$} & Experience Intelligence & $\begin{array}{l}\text { Gathering all relevant data and building an advisory system for future } \\
\text { pandemic management }\end{array}$ \\
\hline & $\begin{array}{c}\text { Post-Pandemic } \\
\text { Restoration Policy }\end{array}$ & Calculating losses in terms of human lives, social and economic impacts. \\
\hline
\end{tabular}

Source: Authors compilation

programs not preventing the fast spread of pandemic taught us lessons of building better and stronger international collaboration. This study shows how significant it would have been for the governments, international, political, and social organizations, leading health organizations, regional and local governments, to have AI systems already in place to assist all phases of managing the pandemic and save more lives in the future. Each government should cooperate together to counter transboundary COVID-19 and similar epidemics in the future. Collaborative capacity built on effective political leadership and a shared vision help partners to coordinate activities and understand their roles, rights, and responsibilities. AI will not only help us fighting against epidemics today in every phases of crisis but will help us to prepare and institutionalize the crisis management better for the future. 


\section{REFERENCES}

Andrew, S. (2020). The World's Fastest Supercomputer Identified Chemicals. Retrieved APRIL 2020 from CNN Web Site, https://edition.cnn.com/2020/03/19/us/fastest-supercomputer-coronavirus-scn-trnd/index.html

Aydın, G., Nyadera, I. N., \& Önder, M. (2020). Strategic Management in Turkey's Public Sector: Reforms and Application Issues. Public Organization Review, 20(4), 719-734. Advance online publication. doi:10.1007/ s11115-020-00463-8

Barth, T. J., \& Arnold, E. (1999). Artificial intelligence and administrative discretion: Implications for public administration. American Review of Public Administration, 29(4), 332-351. doi:10.1177/02750749922064463

Ben Rehouma, M. (2019). Employees' Participation in IT-Projects in the Public Sector. International Journal of Public Administration in the Digital Age, 6(2), 20-34. doi:10.4018/IJPADA.2019040102

Bullock, J., Luccioni, A., Pham, K. H., Lam, C. S. N., \& Luengo-Oroz, M. (2020). Mapping the landscape of artificial intelligence applications against COVID-19. ArXiv, 1-14.

Bullock, J. B. (2019). Artificial Intelligence, Discretion, and Bureaucracy. American Review of Public Administration, 49(7), 751-761. doi:10.1177/0275074019856123

Chamola, V., Hassija, V., Gupta, V., \& Guizani, M. (2020). A Comprehensive Review of the COVID-19 Pandemic and the Role of IoT, Drones, AI, Blockchain, and 5G in Managing Its Impact. IEEE. doi:10.1109/ ACCESS.2020.2992341

Choi, S. O., \& Brower, R. S. (2006). When Practice Matters More than Government Plans: A Network Analysis of Local Emergency Management. Administration \& Society, 37(6), 651-678. doi:10.1177/0095399705282879

Chowdhury, S., \& Chakraborty, P. (2017). Universal health coverage - There is more to it than meets the eye. Journal of Family Medicine and Primary Care, 6(2), 169-170. doi:10.4103/jfmpc.jfmpc PMID:29026777

Christensen, T., Lægreid, P., \& Rykkja, L. H. (2016). Organizing for Crisis Management: Building Governance Capacity and Legitimacy. Public Administration Review, 76(6), 887-897. doi:10.1111/puar.12558

Cohen, J. P., Morrison, P., Dao, L., Roth, K., Duong, T. Q., \& Ghassemi, M. (2020). COVID-19 Image Data Collection: Prospective Predictions Are the Future. February. https://arxiv.org/abs/2006.11988

Correia, T. (2020). SARS-CoV-2 pandemics: The lack of critical reflection addressing short- and long-term challenges. The International Journal of Health Planning and Management, 1-4(3), 669-672. Advance online publication. doi:10.1002/hpm.2977 PMID:32237159

Delivorias, A., \& Scholz, N. (2020). Economic impact of epidemics and pandemics. European Paliamentary Research Service, (February), 1-10.

Dickinson, H. (2018). The Next Industrial Revolution? The Role of Public Administration in Supporting Government to Oversee 3D Printing Technologies. Public Administration Review, 78(6), 922-925. doi:10.1111/ puar. 12988

European Commission. (2020). White Paper on Artificial Intelligence - A European approach to excellence and trust. https://ec.europa.eu/info/consultations_en

European Parliament. (2020). The impact of the General Data Protection Regulation on Social Security. European Parliamentary Research Service. doi:10.1007/s12027-019-00565-x

Feiock, R. C. (2013). The Institutional Collective Action Framework. Policy Studies Journal: the Journal of the Policy Studies Organization, 41(3), 397-425. doi:10.1111/psj.12023

French, P. E., \& Raymond, E. S. (2009). Pandemic influenza planning: An extraordinary ethical dilemma for local government officials. Public Administration Review, 69(5), 823-830. doi:10.1111/j.1540-6210.2009.02032.x

Gozes, O., Frid-Adar, M., Greenspan, H., Browning, P. D., Bernheim, A., \& Siegel, E. (2020). Rapid AI Development Cycle for the Coronavirus (COVID-19) Pandemic: Initial Results for Automated Detection \& Patient Monitoring using Deep Learning CT Image Analysis. https://arxiv.org/abs/2003.05037 
Hart, P. (2001). Public Leadership in Times of Crisis : Mission Impossible? Crisis : A Window for Leadership? Consciousness : Leadership Challenges. Public Administration Review, 63(5), 544-553.

Head, B. W., \& Alford, J. (2015). Wicked Problems: Implications for Public Policy and Management. Administration \& Society, 47(6), 711-739. doi:10.1177/0095399713481601

Henstra, D. (2010). Evaluating local government emergency management programs: What framework should public managers adopt? Public Administration Review, 70(2), 236-246. doi:10.1111/j.1540-6210.2010.02130.x

Hoffman, M. C. (2016). The Responsive City: Big Data versus Big Government. Public Administration Review, 76(4), 684-686. doi:10.1111/puar.12582

Hollister, M. (2020, March 30). AI can help with the COVID-19 crisis - but the right human input is key. Retrieved March 2020, from We Forum https://www.weforum.org/agenda/2020/03/covid-19-crisis-artificialintelligence-creativity/

Hurley, M. W., \& Wallace, W. A. (1986). Expert systems as decision aids for public managers: An assessment of the technology and prototyping as a design strategy. Public Administration Review, 46, 563-571. doi:10.2307/975578

Husain, A. (2020, June 10). Drones vs. Covid-19: Ensuring Airspace Safety And Security With AI. Retrieved July 04, 2020, from https://www.forbes.com/sites/amirhusain/2020/06/10/drones-vs-covid-19-ensuring-airspacesafety-and-security-with-ai/

IBM. (2020). IBM Watson Health. Retrieved March 2020, from IBM: https://www.ibm.com/watson-health/ learn/artificial-intelligence-medicine

Imagining Covid-19 AI. (2020, March 20). Retrieved April 2020, from EUSOMII: https://imagingcovid19ai. eu/\#the-project

Jakhar, D., \& Kaur, I. (2020). Artificial Intelligence for COVID-19. Dermatologic Therapy, 33(4). Advance online publication. doi:10.1111/dth.13654 PMID:32445213

Jiang, X., Coffee, M., Bari, A., Wang, J., Jiang, X., Huang, J., Shi, J., Dai, J., Cai, J., Zhang, T., Wu, Z., He, G., \& Huang, Y. (2020). Towards an Artificial Intelligence Framework for Data-Driven Prediction of Coronavirus Clinical Severity. Towards an Artificial Intelligence Framework for Data-Driven Prediction of Coronavirus Clinical Severity., 63(1), 537-551. doi:10.32604/cmc.2020.010691

Jreisat, J. (2012). Globalism and Comparative Public Administration. CRC Press.

Jung, K., Song, M., \& Park, H. J. (2019). The Dynamics of an Interorganizational Emergency Management Network: Interdependent and Independent Risk Hypotheses. Public Administration Review, 79(2), 225-235. doi:10.1111/puar.12993

Kamel Boulos, M. N., \& Geraghty, E. M. (2020). Geographical tracking and mapping of coronavirus disease COVID-19/severe acute respiratory syndrome coronavirus 2 (SARS-CoV-2) epidemic and associated events around the world: How 21st century GIS technologies are supporting the global fight against outbr. International Journal of Health Geographics, 19(1), 1-12. doi:10.1186/s12942-020-00202-8 PMID:32013994

Kamradt-Scott, A., \& McInnes, C. (2012). The securitization of pandemic influenza: Framing, security and public policy. Global Public Health, 7(2), 95-110. doi:.2012.72575210.1080/17441692

Kaya, T. (2019). Artificial Intelligence Driven E-Government: The Engage Model To Improve E-Decision Making. Proceedings of the 19th European Conference on Digital Government. doi:10.34190/ECDG.19.054

Kushchu, İ. (2020). Artificial Intelligence \& Covid-19: Fighting Pandemics. The Next Minds.

Lai, A. Y. (2012). Organizational collaborative capacity in fighting pandemic crises: A literature review from the public management perspective. Asia-Pacific Journal of Public Health, 24(1), 7-20. doi:10.1177/1010539511429592 PMID:22345395

Maciejewski, M. (2017). To do more, better, faster and more cheaply: Using big data in public administration. International Review of Administrative Sciences, 83(1), 120-135. doi:10.1177/0020852316640058 
Mann, D. M., Chen, J., Chunara, R., Testa, P. A., \& Nov, O. (2020). COVID-19 transforms health care through telemedicine: Evidence from the field. Journal of the American Medical Informatics Association : JAMIA, 27(May), 1132-1135. doi:10.1093/jamia/ocaa072 PMID:32324855

Metabiota. (2020). Monitoring and risk analytics for the 2019 novel coronavirus (COVID-19) epidemic executive. Metabiota. https://metabiota.com/sites/default/files/inline-files/Metabiota_Risk_Report_No.3-25Feb2020COVID-2019_0.pdf

O’Malley, M. (2014). Doing what works: Governing in the age of big data. Public Administration Review, 74(5), 555-556. doi:10.1111/puar.12260

OECD. (2019). Scoping the OECD AI principles: Deliberations of the Expert Group on Artificial Intelligence at the OECD (AIGO). OECD Digital Economy Papers, No. 291. OECD Publishing. doi:10.1787/d62f618a-

OECD. (2020). Using artificial intelligence to help combat COVID-19. https://www.oecd.org/coronavirus/ policy-responses/using-artificial-intelligence-to-help-combat-covid-19-ae4c5c21/

Ojo, A., Mellouli, S., \& Ahmadi Zeleti, F. (2019). A Realist Perspective on AI-era Public Management. Proceedings of the 20th Annual International Conference on Digital Government Research, 159-170. doi:10.1145/3325112.3325261

Onder, M. (2020). Artificial Intelligence: Conceptual framework. in Yapay Zeka Stratejileri ve Türkiye [AI Strategies and Turkey]. ULISA, 12. https://aybu.edu.tr/yulisa/contents/files/ULI\%cc\%87SA_12_Say\%c4\%b1_2_ yapay_zeka.pdf

Onder, M., \& Nyadera, I. N. (2020). Comparative Administrative Cultures between Developed and Developing Countries. In A. Farazmand (Ed.), Global Encyclopedia of Public Administration, Public Policy, and Governance. Springer. doi:10.1007/978-3-319-31816-5_3902-1

Onder, M., \& Saygili, H. (2018). Yapay Zekâ ve Kamu Yönetimine Yansımaları [AI and the Reflections on Public Administration]. Türk İdare Dergisi, 487(90), 629-668.

Paulin, A. A. (2017). Informating Public Governance. International Journal of Public Administration in the Digital Age. International Journal of Public Administration in the Digital Age, 4(2), 14-32. Advance online publication. doi:10.4018/IJPADA.2017040102

Rahman, M. S., Peeri, N. C., Shrestha, N., Zaki, R., Haque, U., \& Hamid, S. H. A. (2020). Defending against the Novel Coronavirus (COVID-19) outbreak: How can the Internet of Things (IoT) help to save the world? Health Policy and Technology, 9(2), 136-138. doi:10.1016/j.hlpt.2020.04.005 PMID:32322475

Rao, A. S. S., \& Vazquez, J. A. (2020). Identification of COVID-19 can be quicker through artificial intelligence framework using a mobile phone-based survey when cities and towns are under quarantine. Infection Control and Hospital Epidemiology, 41(7), 826-830. doi:10.1017/ice.2020.61 PMID:32122430

Richardson, P., Griffin, I., Tucker, C., Smith, D., Oechsle, O., Phelan, A., \& Stebbing, J. (2020). Baricitinib as potential treatment for 2019-nCoV acute respiratory disease. In The Lancet. Elsevier Ltd. doi:10.1016/S01406736(20)30304-4

Simon, H. A. (1965). Administrative decision making. Public Administration Review, $25(1), 31-37$. doi:10.2307/974005

Sousa, W. G., de Melo, E. R. P., Bermejo, P. H. D. S., Farias, R. A. S., \& Gomes, A. O. (2019). How and where is artificial intelligence in the public sector going? A literature review and research agenda. Government Information Quarterly, 36(4), 1-14.

Stebbing, J., Phelan, A., Griffin, I., Tucker, C., Oechsle, O., Smith, D., \& Richardson, P. (2020). COVID-19 : Combining antiviral and anti-inflammatory treatments. The Lancet. Infectious Diseases, $20(4), 400-402$. doi:10.1016/S1473-3099(20)30132-8 PMID:32113509

Sun, L., \& Xue, L. (2020). Does non-destructive earthquake experience affect risk perception and motivate preparedness? Journal of Contingencies and Crisis Management, 28(2), 122-130. doi:10.1111/1468-5973.12286

Ting, D. S. W., Carin, L., Dzau, V., \& Wong, T. Y. (2020). Digital technology and COVID-19. Nature Medicine, 26(4), 459-461. doi:10.1038/s41591-020-0824-5 PMID:32284618 
Uzun, M. (2020). Artificial Intelligence Applications in the Fight Against COVID-19. ULISA, 12, 45-54.

Valle-Cruz, D., Alejandro Ruvalcaba-Gomez, E., Sandoval-Almazan, R., \& Ignacio Criado, J. (2019, June). A review of artificial intelligence in government and its potential from a public policy perspective. Proceedings of the 20th Annual International Conference on Digital Government Research, 91-99. doi:10.1145/3325112.3325242

Wang, C. J., Ng, C. Y., \& Brook, R. H. (2020). Response to COVID-19 in Taiwan: Big Data Analytics, New Technology, and Proactive Testing. Journal of the American Medical Association, 323(14), 1341-1342. doi:10.1001/jama.2020.3151 PMID:32125371

Wang, L., \& Wong, A. (2020). COVID-Net: A Tailored Deep Convolutional Neural Network Design for Detection of COVID-19 Cases from Chest Radiography Images. https://arxiv.org/abs/2003.09871

WHO. (2019). Progress report on HIV, viral hepatitis and sexually transmitted infections, 2019. Who, 53(9), 1689-1699. doi:10.1017/CBO9781107415324.004

Yang, Z., Zeng, Z., Wank, K., Wong, S.-S., \& Liang, W. (2020). Modified SEIR and AI prediction of the epidemics trend of COVID-19 in China under public health interventions. Journal of Thoracic Disease, 12(3), 165-174.

Yildirim, K., \& Onder, M. (2019). Collaborative Role of Metropolitan Municipalities in Local Climate Protection Governance Strategies: The Case of Turkish Metropolitan Cities. Journal of Environmental Assessment Policy and Management, 21(2). https://doi.org/10.1142/S1464333219500066

Yildiz, M., \& Uzun, M. (2020). Koronavirüsle Mücadele Kriz Yönetimi ve Kamu Politikası Yapımı [Crisis Management and Public Policy-Making against Coronavirus]. SETA, 11-13.

Zhavoronkov, A. (2020). Potential 2019-nCoV 3C-like Protease Inhibitors Designed Using Generative Deep Learning Approaches. ChemRxiv. 10.26434/CHEMRXIV.11829102.V1

Murat Onder is a Prof. Dr. at the School of Political Sciences at Ankara Yildirim Beyazit University (AYBU), Turkey. Prof. Onder received his Ph.D. in Public Administration and Policy from Florida State University. Prof. Onder's research interests are in the topics of comparative public administration, strategic management, performance, NGOs, policy analysis, governance, and artificial intelligence.

Mehmet Metin Uzun is a PhD candidate at the Politics, University of Exeter, United Kingdom.. His main research interests include comparative public policy, regulation and artificial intelligence governance. 